\title{
THE EFFECTS OF HONEY BEE (APIS MELLIFERA) QUEEN INSEMINATION VOLUME ON COLONY GROWTH
}

An Undergraduate Research Scholars Thesis

by

ALEXANDRIA NICOLE PAYNE

Submitted to the Undergraduate Research Scholars program Texas A\&M University

in partial fulfillment of the requirements for the designation as an

UNDERGRADUATE RESEARCH SCHOLAR

Approved by

Research Advisor:

Dr. Juliana Rangel

May 2016

Major: Bioenvironmental Sciences

Wildlife and Fisheries Sciences 


\section{TABLE OF CONTENTS}

Page

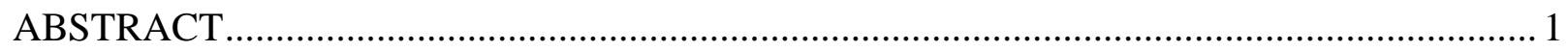

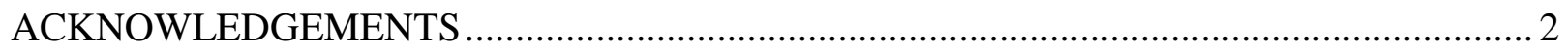

CHAPTER

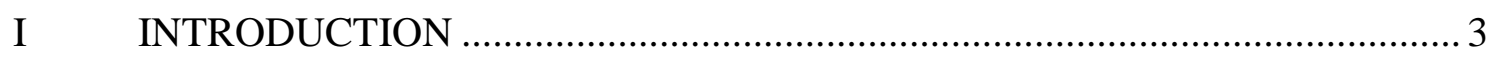

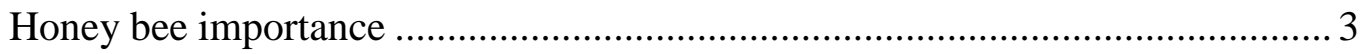

The reproductive potential of honey bee queens .................................................. 3

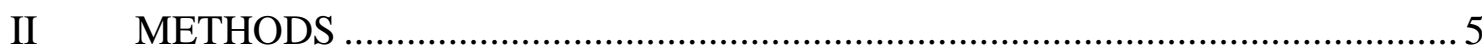

Establishing colonies and the insemination of queens.......................................... 5

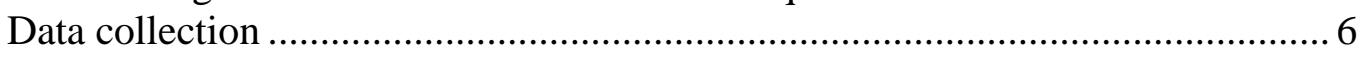

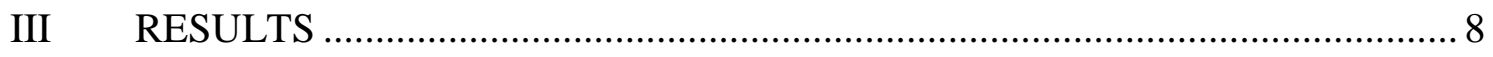

Statistical significance of data ....................................................................... 8

Figures depicting colony growth parameters ...................................................... 8

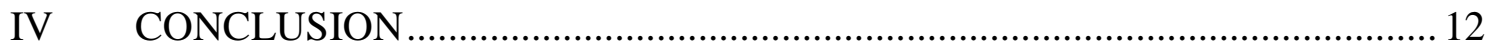

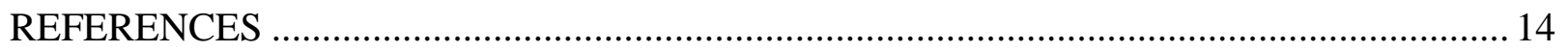




\begin{abstract}
The Effects of Honey Bee (Apis mellifera) Queen Insemination Volume on Colony Growth

Alexandria Payne

Department of Entomology

Texas A\&M University

Research Advisor: Dr. Juliana Rangel

Department of Entomology
\end{abstract}

The honey bee (Apis mellifera) is a eusocial insect where each individual hive contains a single, polyandrous queen that is responsible for laying the fertilized eggs that maintain a hive's worker population. Virgin queens will go on mating flights during a single period of time at the beginning of their lifespan and mate with an average of 12 drone bees. The sperm that is collected in the reproductive organ known as the spermatheca will be the only amount of sperm available to a queen for the duration of her lifetime. The quality of a hive has been shown in past studies to be dependent on the quality of its queen. This study looks at how the volume of semen a queen is artificially inseminated with affects the overall growth of a colony over time by comparing hives led by high-inseminated queens (those artificially inseminated with $9 \mathrm{uL}$ of semen) to hives led by low-inseminated queens (those artificially inseminated with $1.5 \mathrm{uL}$ of semen). The parameters that were measured as part of colony growth included the population of a hive, the amount of worker and drone comb built, the amount of capped worker and drone brood, and the amount of food stored within each of the experimental hives. The results of this study showed that there were not any statistically significant differences in any measure of colony growth between the hives led by queens inseminated with a low semen volume compared to queens inseminated with a high semen volume. 


\section{AKNOWLEDGEMENTS}

I would like to first thank Dr. Juliana Rangel for serving as my advisor and giving me the opportunity to conduct research in her lab. I would also like to thank Susan Cobey for her assistance in the artificial insemination of the queens used in this experiment, and thanks also go to Dr. Jane Packard as well for her help in the statistical analysis of this data. I would also like to recognize and say thank you to the members of the Rangel lab who assisted me in the tedious task of data collection including Lauren Ward, Elizabeth Walsh, and Pierre Lau. 


\section{CHAPTER I}

\section{INTRODUCTION}

\section{Honey bee importance}

The health of honey bee (Apis mellifera) populations has been a hot topic in the past decade due to the decline of hives resulting from such factors as parasites, pesticide use, and malnutrition (Potts et al. 2010). Preserving the health of honey bee colonies and conducting research pertaining to their health is crucial for a number of reasons including for agricultural practices and maintaining global food security. It has been estimated that honey bees contribute about $\$ 17$ billion annually to the United States' economy through their pollination services of agriculturally important crops. This estimate does not take into account the revenue gained from products directly produced by honey bee colonies such as honey and beeswax (Morse and Calderon 2003). These pollinators also play a large role in maintaining global food security as they are estimated to be responsible for 35\% of the world's overall food production (Klein et al. 2007).

\section{The reproductive potential of honey bee queens}

A honey bee colony is typically composed of a single, fertile queen, several thousand sterile, female workers, and a few hundred seasonal drone (male) bees. The queen follows a haplodiploid sex-determination system and is an important part of a hive's health as she is the sole individual responsible for laying the eggs which maintain a hive's worker population (Dzierzon 1845). If a honey bee queen were to lay a haploid (unfertilized) egg, it would hatch into a drone bee. If a diploid (fertilized) egg were to be laid, then a female worker or a virgin queen would emerge depending on the diet fed the developing larvae. Virgin queens will go on 
mating flights shortly after their emergence from an egg and mate with an average of 12 drones (about $7 \mathrm{uL}$ worth of semen) where the collected sperm is stored in a reproductive organ known as the spermatheca (Tarpy et al. 2004). This is the only instance in a queen's lifespan where she will mate and thus the only time period where she will receive sperm to fertilize her eggs and produce female workers and future virgin queens. The sperm that a honey bee queen collects is thus what she has to make do with for the rest of her lifespan (Winston 1987). Once a queen depletes her store of semen, she is then only able to lay unfertilized eggs that develop into drones whose sole function is reproduction and thus do not contribute to the maintenance and growth of a colony. In some instances, the workers of a colony will undergo a process known as supersedure if they deem the quality of a honey bee queen to be too low due to such factors as low pheromone or egg production (Hooper \& Morse 1985). This process involves the workers raising multiple queen larvae where one of these larvae will eventually replace the existing, low quality queen. The reproductive potential of queens and the quality of such characteristics as physiology and pheromone production has been shown in past studies to be dependent on the volume of sperm a queen collects on mating flights (Niño et al. 2012, Rangel, Keller, and Tarpy 2012). The purpose of this particular study is to look at the effects that queen insemination volume has on colony growth as this aspect of a queen's reproductive potential has yet to be determined. 


\section{CHAPTER II}

\section{METHODS}

\section{Establishing colonies and the insemination of queens}

This experiment took place at the Honey Bee Research Facility located at the Riverside campus of Texas A\&M University in Bryan, TX (30³8'3.60"N, 96²7'56.83"W). All experimental queens used throughout the study were taken from a single source colony in order to minimize the effects of genetic variation following established protocols as outlined in Tarpy and Mayer, 2009. The experimental queens were then raised based on standard queen rearing techniques and procedures (Laidlaw and Page, 1997).

The honey bee queens were separated into two, nearly equal experimental groups that consisted of high-quality (high insemination volume) queens and low-quality (low insemination volume) queens. Nine of the experimental hives consisted of high-quality queens artificially inseminated with $9 \mathrm{uL}$ of semen (considered an above-average semen volume for naturally inseminated queens). The other ten experimental hives in the study consisted of low-quality queens artificially inseminated with about $1.5 \mathrm{uL}$ of semen (considered a low semen volume for naturally inseminated queens). Artificial insemination of all experimental honey bee queens was performed by Susan Cobey (an internationally recognized expert in the field of instrumental insemination and honey bee breeding). Artificial insemination was performed in order to more accurately determine the volume of semen contained in the spermatheca of each experimental queen. Natural insemination of queens was not an option for this experiment as determining the insemination volume of naturally inseminated queens requires the removal of the spermatheca 
which results in the death of the queen. Each queen was labeled with a paint mark on the thorax according to her experimental group along with having one wing clipped. These markings allowed for the precise identification of experimental queens in case one were to die or be superseced at some point through the experimental process.

The first set of hives was established on May $13^{\text {th }}$ and contained 5 low inseminated and 5 high inseminated queen colonies. The second set of hives was established on June $8^{\text {th }}$ and contained 5 low inseminated and 4 high inseminated queen colonies. Each experimental queen were placed into a distinct colony that contained an equal starting amount of resources compared to the other colonies including initial worker population, brood, and food (Rangel, Keller, and Tarpy 2012). Each colony was established with about 2 pounds worth of worker bees. This roughly translates into an initial worker population of about 6984 bees per colony. Colonies were established with alternating full and partial frames in order to allow for the production of drone comb on partial frames in the hives. Additional frames were added throughout the experiment to any hive whose honeycomb production extended to all existing frames.

\section{Data collection}

The growth of each colony was measured and recorded on a biweekly schedule from the establishment date of a hive until October 2015. The first set of hives had an additional sampling bout where data was collected due to the first set's earlier establishment date. The parameters of colony growth measured in this experiment consisted of the hive's population, the amount of honey comb built (both worker and drone), the amount of sealed worker and drone brood (the 
number of female and male eggs laid by the queen respectively), and the amount of food storage (honey, nectar, and pollen). Measurements were taken with a gridded, wooden frame as shown in Figure 1. This frame consisted of 136, 1 x 1 inch squares. The population of each hive was estimated using point sampling by counting the number of individual bees in 20 pre-determined, evenly spaced squares on each side of each frame. The resulting population was then extrapolated to estimate the total population of each colony. The amount of squares containing built worker comb, drone comb, sealed worker brood, sealed drone brood, and food storage were also counted and estimated for each frame in each hive (Rangel, Keller, and Tarpy 2012). If a hive were to collapse or supersede for whatever reason, the previous collected data would be retained for the purpose of analysis, but further collection of data would not be performed on the collapsed/superseded hives.

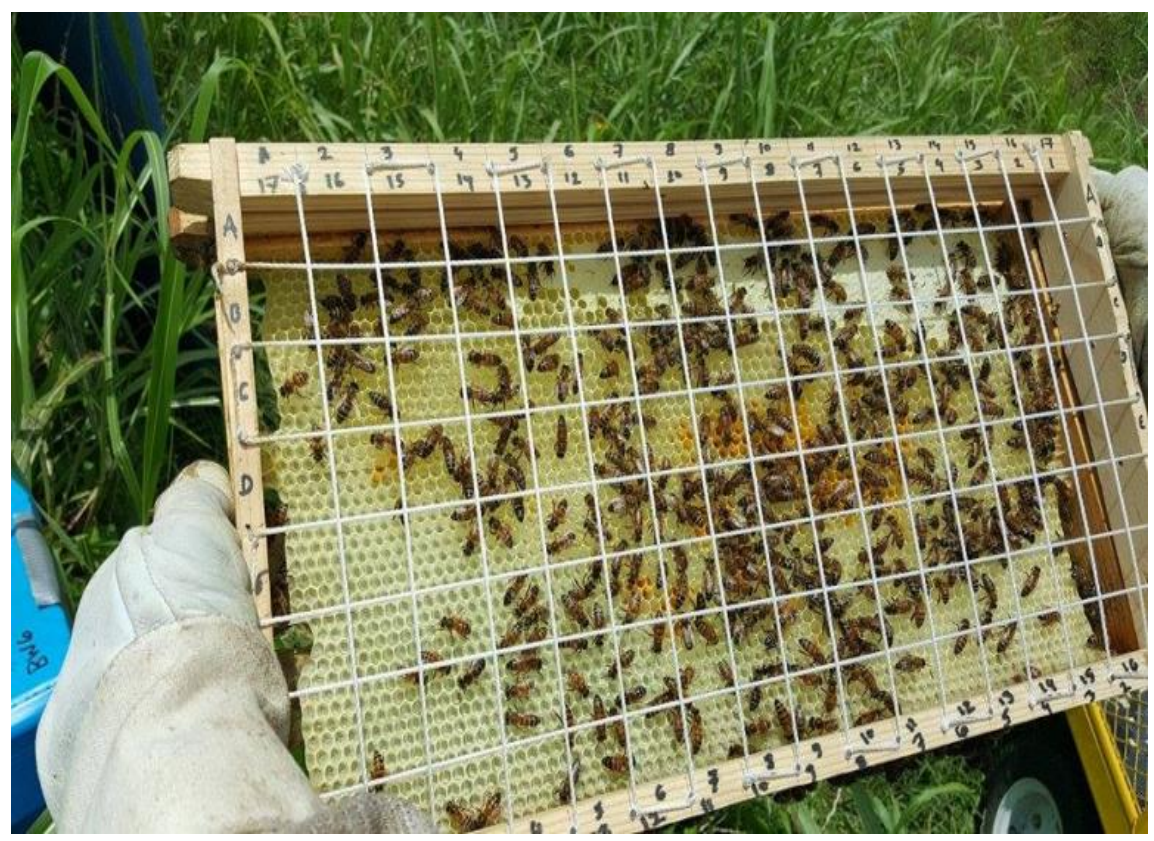

Figure 1: Gridded, wooden frame used to measure the parameters of colony growth 


\section{CHAPTER III}

\section{RESULTS}

\section{Statistical significance of data}

It was found that there were not any overall statistical significant differences in any measure of colony growth (population, worker/drone comb, worker/drone brood, and food storage) between hives led by queens inseminated with a low semen volume $(1.5 \mathrm{uL})$ to hives led by queens inseminated with a high semen volume $(9 \mathrm{uL})$. Statistical analysis and acquisition of $\mathrm{p}$ values was accomplished using JMP Software. The graphs depicting the different parameters of colony growth over time between the two experimental groups can be seen in Figures 2-7.

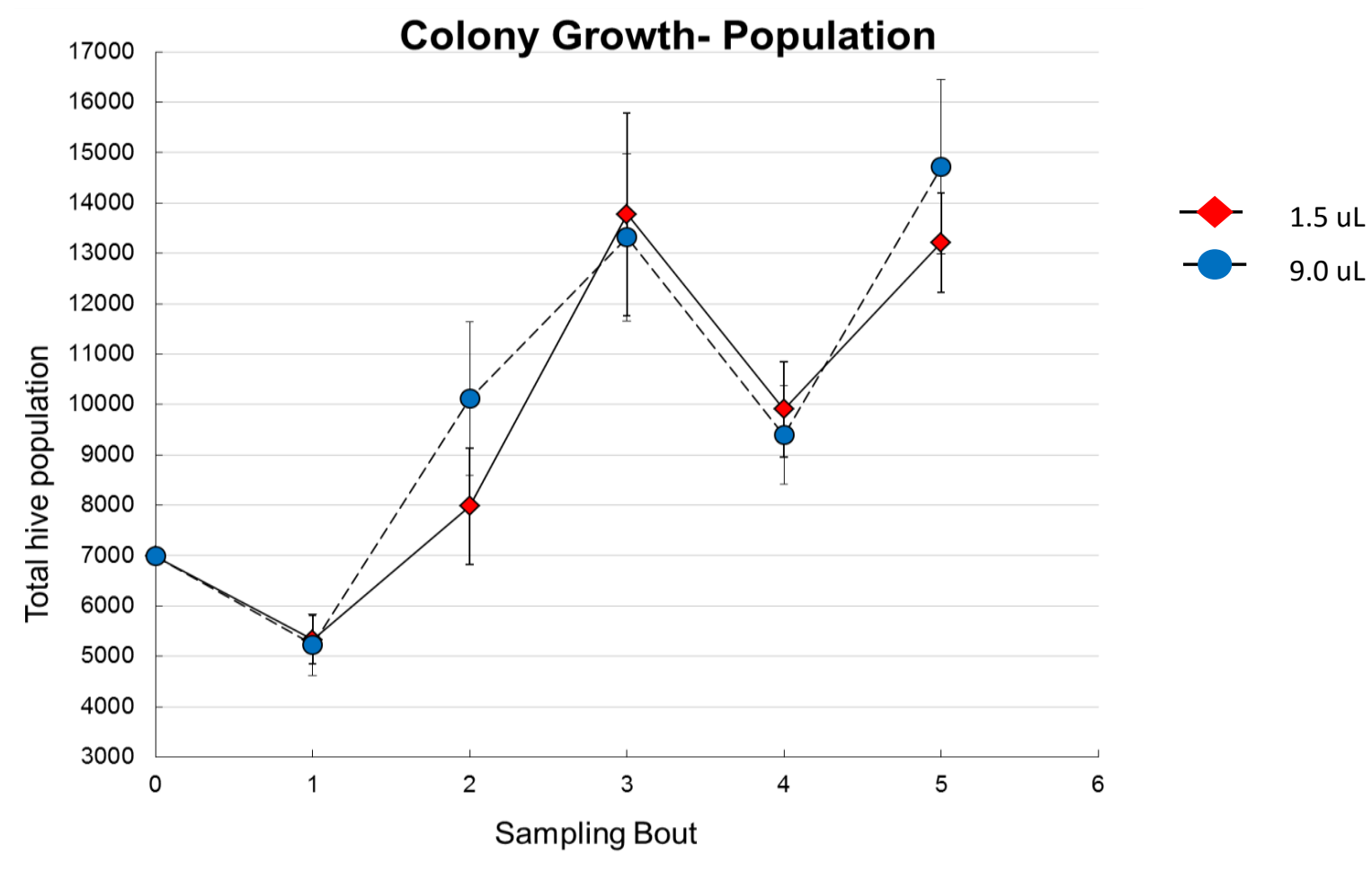

Figure 2: Population growth of the two experimental groups over time. Statistical analysis showed the $p$ value of this colony growth parameter to be 0.219 . 


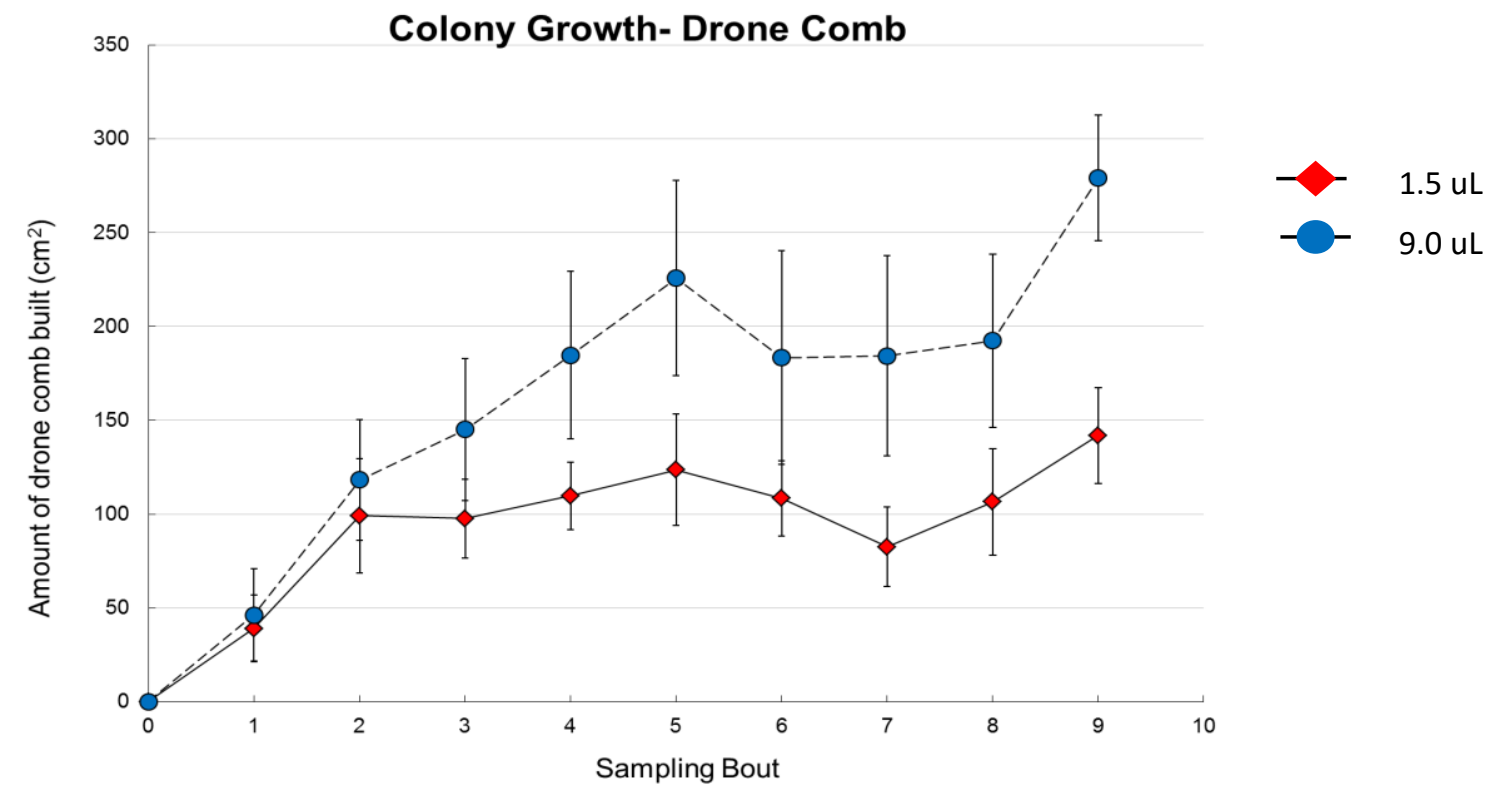

Figure 3: Drone comb growth of the two experimental groups over time. Statistical analysis showed the $p$ value of this colony growth parameter to be 0.354 .

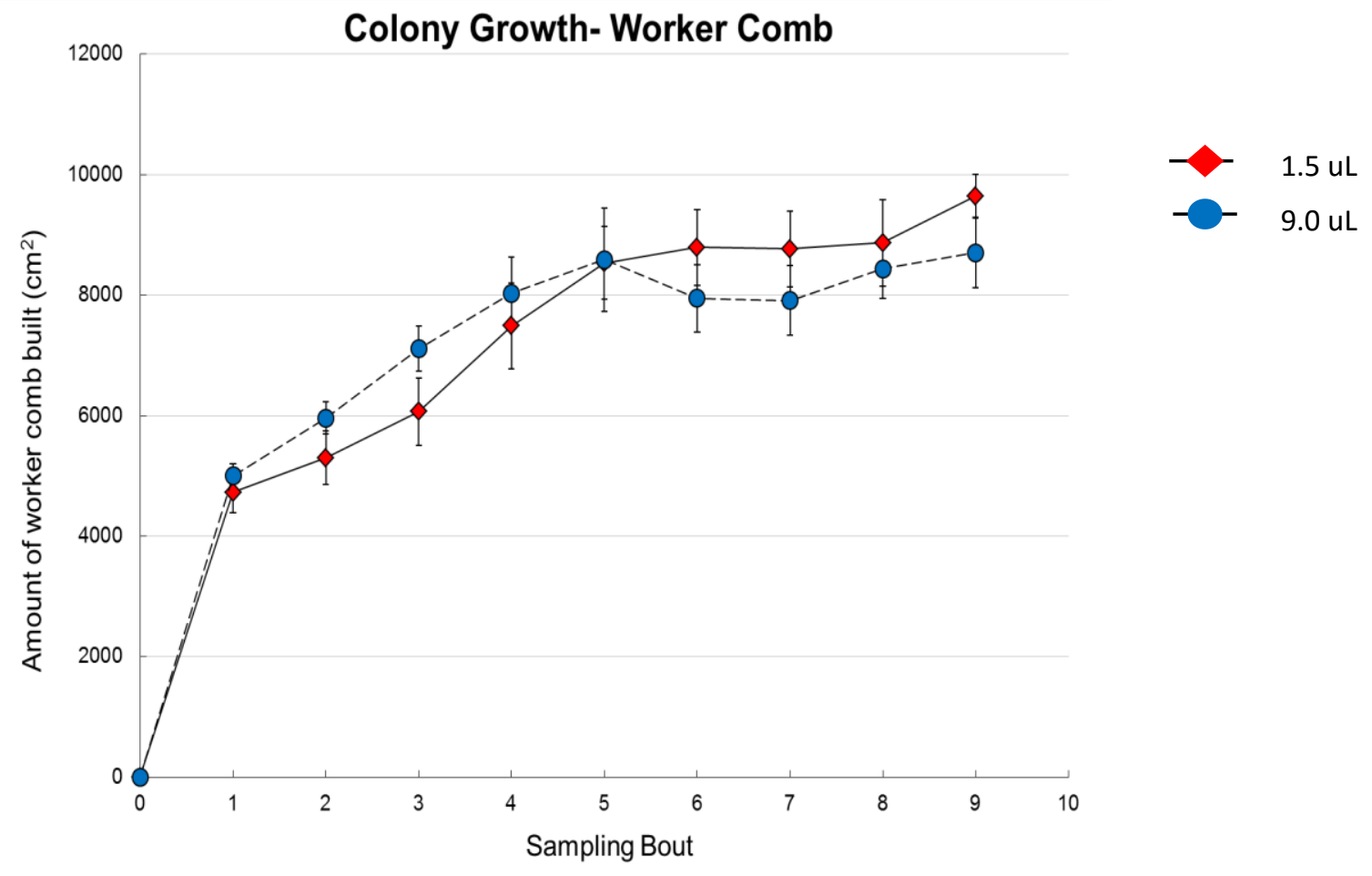

Figure 4: Worker comb growth of the two experimental groups over time. Statistical analysis showed the $p$ value of this colony growth parameter to be 0.573 . 


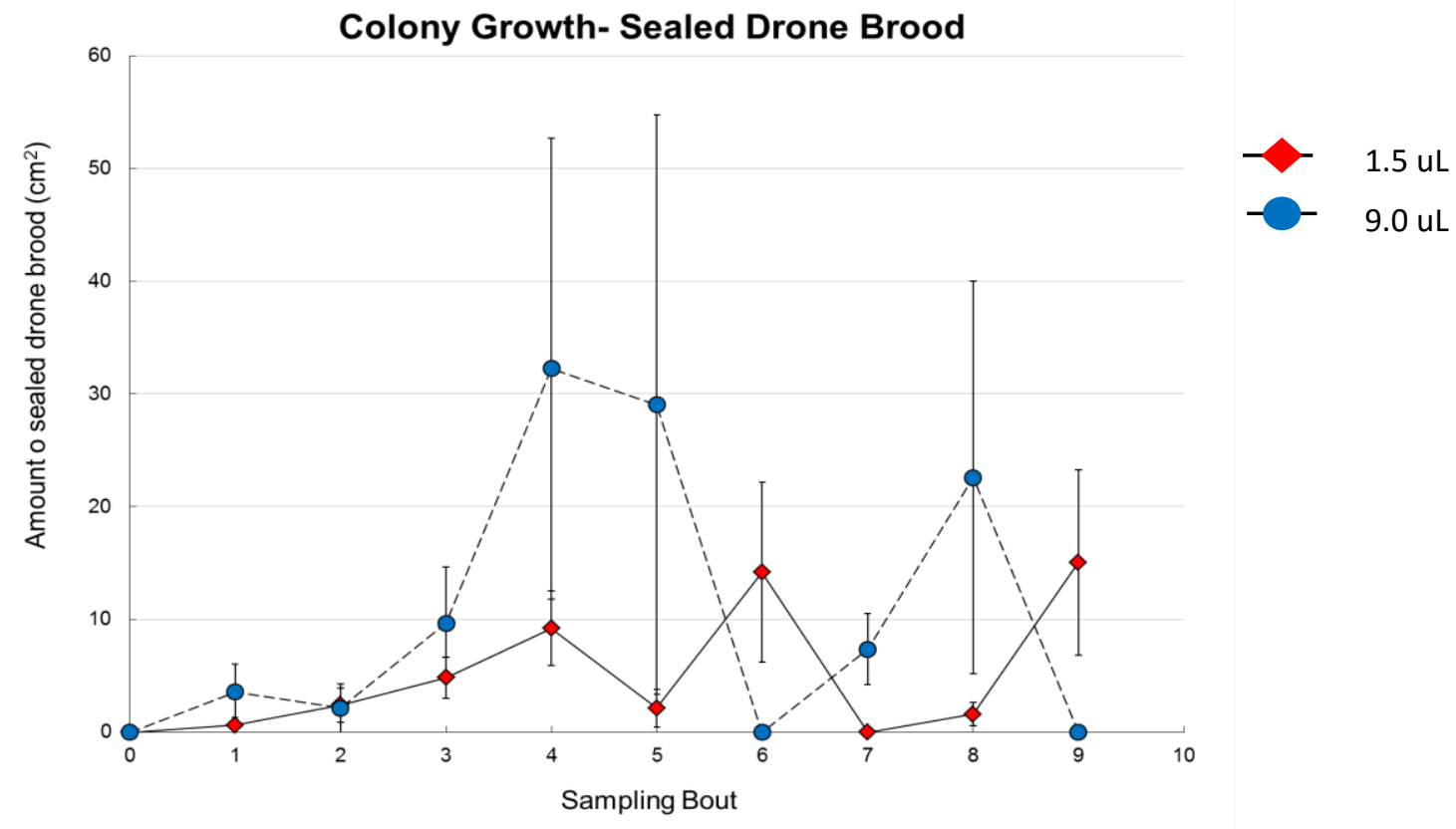

Figure 5: Sealed drone brood growth of the two experimental groups over time. Statistical analysis showed the $p$ value of this colony growth parameter to be 0.313 .

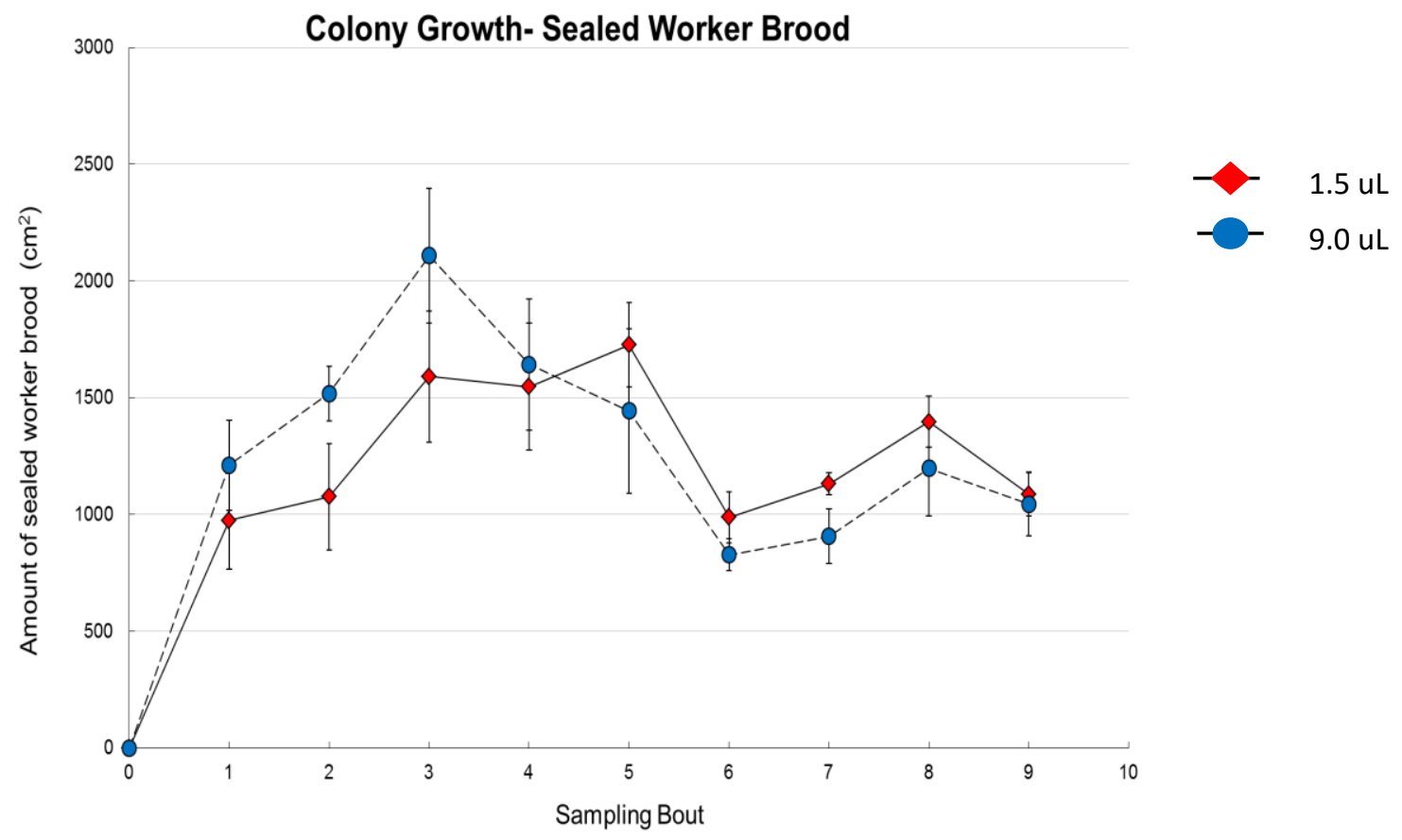

Figure 6: Sealed worker brood growth of the two experimental groups over time. Statistical analysis showed the $p$ value of this colony growth parameter to be 0.356 . 


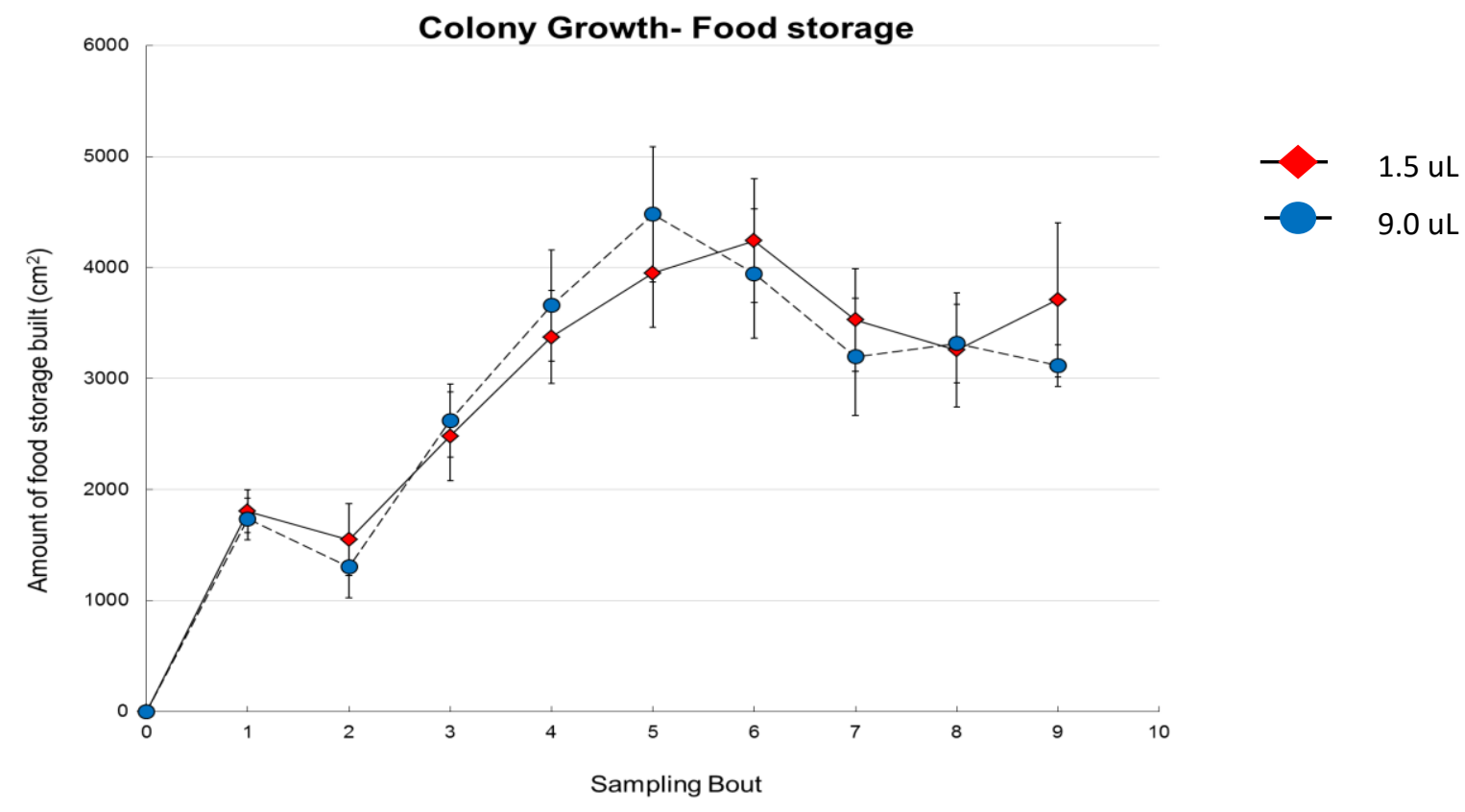

Figure 7: Food storage growth of the two experimental groups over time. Statistical analysis showed the $p$ value of this colony growth parameter to be 0.924 . 


\section{CHAPTER IV}

\section{CONCLUSION}

Although insemination volume of honey bee queens was not found to have a statistical significance on the colony growth parameters outlined in this experiment, the data and results produced by this research add to the general body of existing knowledge on honey bee queen health and reproduction.

Of the initial 9 queens that were in the high inseminated experimental group, 6 survived through the entirety of the data collection period. The low inseminated experimental group initially contained 10 queens, but only 4 survived to the end of the data collection period. The survivability of a hive over the course of the experiment was thought to maybe have a potential effect on the trends of colony growth between the two experimental groups. Although survival was higher in the high inseminated experimental group, a chi-square and Fisher's exact test for hive survival showed that there was not any statistical significance in survivability between the high and low inseminated queens. This resulted in the inability to reject that variation in survivability between queens artificially inseminated with a low vs. high semen volume was due to chance.

Large standard error bars and variability can be seen in Figures 3 and 5 that show drone comb and brood growth respectively. This is due to the low amount of drone comb and brood produced in a hive if produced at all. Drone production is low in the fall season and can be seen in the drop off of sealed drone brood produced in the later sampling bouts in Figure 5. 
The impact of having two different sets of hives with two different establishment dates was taken into consideration when performing analysis. By using a Mann-Whitney U test, it was determined that having two different sets of hives did not have a significant impact on the amount of worker/drone comb built, worker/drone brood produced, or food storages in each of the experimental hives. It was found however that having two hive sets did have a significant impact on the population estimated for each hive. The later establishment date of the second set of hives and the slower start later in the summer season compared to the first set of hives may be the reason behind this significance concerning population. Based on this information, a uniform establishment date of all experimental hives would be required of a future study in order to more accurately determine the effect that queen insemination volume has on a colony's population.

Experimental variation between the two experimental groups may have been impacted by unaccounted factors such as the variation in weather over the sampling season, the availability of food resources in the apiary, or the effects of robbing that occurred during the last two sampling bouts taken. In order to better account for these factors and in general obtain a larger sampling size, another season's worth of data should be collected in order to account for possible variation. A future season of data collection with a uniform establishment date for all hives may uncover varying results for population then those found in this experiment. Further research into whether or not the insemination volume of honey bee queens has an effect on colony growth could potentially look at how hives with artificially inseminated queens differ in their overwintering stage and spring growth stages. This could possibly show that insemination volume does have an impact once the low inseminated queens begin to theoretically run out of sperm prior to the high inseminated queens in the year following insemination. 


\section{REFERENCES}

Dzierzon, J. (1845). Gutachten über die von herrn direktor stöhr im ersten und zweiten kapitel des general-gutachtens aufgestellten fragen. Eichstädter Bienenzeitung, 1(109-113), 109113.

Hooper, T. \& Morse, R. 1985. Supersedure. In: The illustrated encyclopaedia of beekeeping, p. 370. Butler and Tanner Ltd, Frome, Somerset, U.K. ISBN 0-7137-1624-X.

Klein, A.-M., Vaissière, B. E., Cane, J. H., Steffan-Dewenter, I., Cunningham, S. A., Kremen, C., \& Tscharntke, T. (2007). Importance of pollinators in changing landscapes for world crops. Proceedings of the Royal Society B: Biological Sciences, 274(1608), 303-313.

Laidlaw H.H. Jr. and Page R. Jr. 1997. Queen Rearing and Bee Breeding. Wicwas, Cheshire, CT.

Morse, Roger A., and Nicholas W. Calderone. "The Value of Honey Bees As Pollinators of U.S. Crops in 2000." Bee Culture Magazine 13 June 2003: 1-15.

Niño, Elina L., Osnat Malka, Abraham Hefetz, Peter Teal, Jerry Hayes, and Christina M. Grozinger. "Effects of Honey Bee (Apis Mellifera L.) Queen Insemination Volume on Worker Behavior and Physiology." Journal of Insect Physiology 58.8 (2012): 1082-089.

Potts, S. G., Biesmeijer, J. C., Kremen, C., Neumann, P., Schweiger, O., \& Kunin, W. E. (2010). Global pollinator declines: trends, impacts and drivers.Trends in ecology \& evolution, 25(6), 345-353.

Rangel, J., J. J. Keller, and D. R. Tarpy. "The Effects of Honey Bee (Apis Mellifera L.) Queen Reproductive Potential on Colony Growth."Insectes Sociaux Insect. Soc. 60.1 (2012): 6573.

Tarpy D.R. and Mayer M.K. 2009. The effects of size and reproductive quality on the outcomes of duels between honey bee queens (Apis mellifera L.). Ethol. Ecol. Evol. 21: 147-153.

Tarpy, D., Nielsen, R., Nielsen, D., 2004. A scientific note on the revised estimates of effective paternity frequency in Apis. Insectes Sociaux 51 (2), 203-204.

Wilson, E. O. (1971). The insect societies. The insect societies.

Winston, M.L., 1987. The biology of the honey bee. MA, Harvard University Press, Cambridge. 